IRA-International Journal of Management \&

Social Sciences

ISSN 2455-2267; Vol.16, Issue 02 (April-June 2020)

Pg. no. 59-67.

Institute of Research Advances

http://research-advances.org/index.php/RAJMSS

\title{
Relevance of Work-Life Balance in India - A Skeptical Analysis among Teaching Professionals
}

\section{Dr. Rubavel M}

Assistant Professor, Department of Social Work, Kristu Jayanti College, K. Narayanapura, Kothanur, Bengaluru Karnataka-560077

Type of Work: Peer Reviewed.

DOl: http://dx.doi.org/10.21013/jmss.v16.n2.p3

\section{How to cite this paper:}

Rubavel, M. (2020). Relevance of Work-Life Balance in India - A Skeptical Analysis among Teaching Professionals. IRA-International Journal of Management \& Social Sciences (ISSN 24552267), 16(2), 59-67. doi:http://dx.doi.org/10.21013/jmss.v16.n2.p3

(C) Institute of Research Advances.

(cc) BY-NC

This work is licensed under a Creative Commons Attribution-Non Commercial 4.0 International License subject to a proper citation to the publication source of the work.

Disclaimer: The scholarly papers as reviewed and published by the Institute of Research Advances (IRA) are the views and opinions of their respective authors and are not the views or opinions of the IRA. The IRA disclaims of any harm or loss caused due to the published content to any party.

Institute of Research Advances is an institutional publisher member of Publishers International Linking Association Inc. (PILA-CrossRef), USA. The institute is an institutional signatory to the Budapest Open Access Initiative, Hungary advocating the open-access of scientific and scholarly knowledge. The Institute is a registered content provider under Open Access Initiative Protocol for Metadata Harvesting (OAI-PMH).

The journal is indexed \& included in WorldCat Discovery Service (USA), CrossRef Metadata Search (USA), WorldCat (USA), OCLC (USA), Open J-Gate (India), EZB (Germany) Scilit (Switzerland), Airiti (China), Bielefeld Academic Search Engine (BASE) of Bielefeld University, Germany, PKP Index of Simon Fraser University, Canada. 


\begin{abstract}
A person has to balance the work and life in all walks of his life. Due to social change in the society, the type of households is changing from the joint family to nuclear family. The family, work, and society demand equal attention and obligation. The person has to balance the work to family interference and family to work interference. The work-life balance has been adopted by various corporate and organization. This paper reviews how various professionals manage work and life. Some factors influence the work-life balance in the day to day life. It is the greatest task for retaining the manpower in an institution. It is important to facilitate the employee to maintain a work-life balance. There are different kinds of professionals who face challenges in managing work-life balance. It is assumed that the teacher with more children finds difficulty in balancing work-life balance than the childless teacher. She may perceive a better work-life balance. The male teachers may experience a higher degree of burnt out than female teachers. These views helped the author to explore the factors involved in balancing work-life balance and to provide suggestions to manage the work-life. The author has taken up empirical study, this paper focuses on understanding the situation of teachers \& faculties in terms of Work-life balance, Factor involved in work-life balance, and to provide suggestions to manage work-life balance in the teaching profession.
\end{abstract}

Key Words: Work-Life Balance, Satisfaction, Well Being, and Emotional Intelligence.

\title{
Introduction
}

It is due to Industrialization, Urbanization, Globalization, and Technology advancement the social life has undergone changes in human life. The person who can manage work balance life may get job satisfaction. The imbalance between organizational and personal commitment leads to a problem in the work-life as well as in the family. It is an important task of the organization to keeping the workforce. It is a difficult job to retain the manpower within the organization. The retaining of manpower demands facilitating work-life balance within the organization. Institutions need to understand whether the employees can manage the work-life balance or not. The previous studies reveal that burnout in the workplace has a positive relationship with job satisfaction. A person with good well being can manage the work-life balance. The socialization also helps to maintain a work-life balance. The women teachers who take multiple roles may tend to face difficulties to manage work-life balance. The experienced faculty members can able to manage the workload and able to balance work life. Many studies have concluded flexible work time strategy has improved employee productivity, reduction of work-family conflict, and lessen employee turnover in the organization. Work-life balance has become an important tool to maintain and increase the efficiency among the employee in the organization. Kodz et al., (2002) explained, the principle of work-life balance is that "there should be a balance between an individual's work and his life outside work. The organization has to check that the employees can balance work life and should work towards developing a mechanism to ensure the work-life balance among the teachers and Faculties.

It is more important to know the situation of teachers and faculty members in colleges and the factors associated with ensuring work-life balance for retaining manpower in the organizations. This paper explores the situational analysis of teaches and faculty members of colleges, factors associated to balance the work-life, and provide suggestions to manage work-life balance.

\section{Method and materials}

This is an empirical study used convenient sampling among 30 teachers and faculty members in the colleges in Bengaluru city, Karnataka. The questionnaire prepared and collected data from the teachers and faculties in college. The results have been analyzed and presented in this paper.

\section{Objective of the study}

- To understand the situation of work-life balance among teachers and faculty members.

- To study the factors involved in the work-life balance.

- To provide suggestions to manage the work-life balance. 


\section{Review of Literature}

J.Karunyal et.al (2015) According to the study factors have been studied among women workers in the teaching faculties of an American college, South India. The factors have contributed such as the Number of children $18.3 \%$, Health $45 \%$, Laziness $15 \%$, and Responsibility $21.7 \%$. It reveals that Health condition and Family responsibilities significantly contribute to managing the work-life balance. It's recommended that women can take-up part-time work for managing work-life balance and reduced stress in the family. However, the studies reveal that service sector employees were able to manage work-life balance.

Thriveni Kumari K (2015) the study revealed that the respondents of service sectors can balance their work life and personal life. This reveals that $76.4 \%$ of respondents say they can balance their personal life and Work. It is found that a considerable percentage of persons of service sector employees were able to manage work-life balance. $17.8 \%$ of respondents are neutral in their response and $5.8 \%$ of respondents articulated that they were unable to balance their work-life.

Vijay Mani (2013) has revealed the major factors influencing the Work-Life Balance of Women professionals in India such as role conflict, lack of recognition, organizational politics, gender discrimination, and elderly and children care issues, quality of health, problems in time management and lack of proper social support. These barriers push women to not able to manage work-life balance. These barriers to be addressed and Employee should be supported to come out of the barriers by the organization.

Diljot Soin (2011) Part-time teachers are having better well being, lesser stress, and able to maintain a work-life balance.

McCrae \& John (2004) proposed Big Five-factor model of personality traits in terms of five basic dimensions namely: (i) extraversion - describing active, assertive, energetic, enthusiastic and sociable individuals (ii) Agreeableness- characterizing cooperation, forgivingness, kindness and trust, (iii) Conscientiousness- about achievement orientation, dependability, orderliness, efficiency, responsibility and hardworking, (iv) Neuroticismreferring to anxiety, insecurity, tension, and worry (v) Openness to Experience - characterized by intelligence, imagination, curiosity, creativity, and originality.

Ward and Sloane (2000) concluded that there are significant differences in job satisfaction levels based on the gender and disciplinary affiliation of faculty members. Marital relationship, attitude, and cooperation of husband and family members were the other factors that may help to manage the Work-Life Balance amidst working women. The full-time working women may face relatively higher levels of stress with lower levels of psychological well being and consequently lower levels of Work-Life Balance compared to the part-time working women.

Gunavathy (2007) in the study among married women employees of BPO companies outlined and revealed that more than two-thirds of the respondents reported work-life imbalance primarily on account of work interference with personal life. Also concluded stress and burnout, ill-health, and poor work performance are the consequences of work-life imbalance.

\section{Factors influencing the work-life balance}

Different factors influence work-life balance such as Job Satisfaction, Perception of Persons, Emotional Inelegance of Leader, and well being of the person are important factors of work-life balance. There are other factors such as Nature of Job, No. of years of previous experience, Level of hierarchy in the organization, Unclear responsibilities and expectations, Support from the employer and management, Support from colleagues, Policies of the 
organization, Technology and its use, Long Working Hours and Excessive workload (Ritu Atheya \& Renu Arora,2014). However, the different work situations bring challenges to balance the work-life. It is important to help the person to balance the work-life balance for retaining the manpower and improving the productivity.

\section{Challenges and Ability Manage Work-Life Balance}

The ability to manage the Work-life balance is an important aspect of the life. It is also important to look for sufficient scope and choices are given to the worker to manage the work-life balance. It is an important concern that they should be supported to manage work-life balance.

Challenges faced to manage Work-Life Balance

Table - 1

\begin{tabular}{|c|c|c|}
\hline Variables & Response & Percentage \\
\hline \multirow{2}{*}{ Ability to manage work-life Balance } & Yes & 93.3 \\
No & 6.7 \\
\hline Getting excessive Work Load in a & Yes & 73.3 \\
workplace & No & 26.7 \\
\hline \multirow{2}{*}{ Working Long working Hours } & Yes & 60.0 \\
& No & 40.0 \\
\hline \multirow{2}{*}{ Feeling of Stress } & Yes & 56.7 \\
& No & 43.3 \\
\hline \multirow{2}{*}{ Getting Tension frequently } & Yes & 43.3 \\
& No & 56.7 \\
\hline \multirow{2}{*}{ Getting angry frequently } & Yes & 33.3 \\
& No & 66.7 \\
\hline
\end{tabular}

This study reveals that most of them that around 93.3 percentages of the persons can manage work-life balance. However, it is found that many of the teachers are facing the challenges by getting excessive workload, working for long hours apart from official hours, Feeling stressed, getting tension and anger frequently. Challenges seem to be alarming in terms of work-life balance.

\section{Effects of laziness in balancing the work-life balance}

Laziness is an important factor which affects the work-life balance. It is because of laziness person may not work hard to complete work and they tend to postpone the work. This study has found that 26.7 percentages of teachers are expressed that they are lazy in their activities. It indicates that one-fourth of the respondents are Lazy. They may not able to balance the work-life balance. According to J.Karunyal et.al (2015) found that around 15 percentages of people are lazy in earlier studies. This is reaffirming that Laziness is one of the important factors in balancing Worklife balance.

\section{Getting Excessive Work Load and long working hours}

It is difficult to cope - up with the excessive workload and facing this issue a challenge. This study found that 73.3 percent of teachers expressed that they are getting excessive workload which pushes into not able to manage the work. Excessive workload may push them to not able to manage work-life balance. A person who gets excessive workload prone to work long hours this study reveals that around 60 percentages of teachers are spending more time completing the work. It is found that more than half of the population is at risk of the ability to manage the work-life balance. 


\section{Stress, Tension and Anger}

There is a possibility when they are not able to balance the work-life when they get excessive workload and working long hours pushes that teachers are not able to balance the work-life. They may tend to get a lot of stress and tension and Angry. This study reveals that 56.7 percentages of the persons are stressed in the job. It is also found that 43.3 percentages of persons are getting tension at the workplace and 33.3 percentages of persons are getting angry in the workplace. It is found that the symptoms are alarming which may turn into not able to manage the work-life balance.

\section{Coping Mechanism to manage Work-Life Balance}

\section{Job Satisfaction}

The primary factors are job satisfaction, perception of the organization, well being, and emotional intelligence of the leader. Job satisfaction is one of the factors that influence the work-life balance among the working professionals. The job satisfaction is quoted by Heather Schuck (2013) as "You will never feel truly satisfied by work until you are satisfied with life." This factor reinforces that life satisfaction leads to job satisfaction. It pushes to know that whether the faculty members have satisfied in life rather than getting job satisfaction.

\section{Coping Mechanism to manage Work-Life Balance}

Table - 2

\begin{tabular}{|c|c|c|}
\hline Variable & Response & Percentage \\
\hline \multirow{2}{*}{ Job Satisfaction } & Yes & 93.3 \\
& No & 6.7 \\
\hline Understanding by the immediate & Yes & 86.7 \\
Supervisor & No & 13.3 \\
\hline Clear Responsibility from Immediate & Yes & 80.0 \\
Supervisors & No & 20.0 \\
\hline \multirow{2}{*}{ Trusting the Co-Worker } & Yes & 93.3 \\
& No & 6.7 \\
\hline \multirow{2}{*}{ Support form Co-Worker } & Yes & 90.0 \\
& No & 10.0 \\
\hline Technology Support for Work-Life & Yes & 93.3 \\
Balance & No & 6.7 \\
\hline
\end{tabular}

However, the factor that contributes to job satisfaction is to be studied to facilitate job satisfaction. It is suggested to facilitate the manpower to attain life satisfaction. This study reveals that 93.3 percent of persons expressed that they get job satisfaction. Job Satisfaction is an important stepping stone to work with commitment and dedication. It is only 6.7 percentage of persons are not getting job satisfaction. Society of Human Resource Management (SHRM) in 2002 showed $70 \%$ of employees report an unhealthy balance between their work and personal lives. Personal and job satisfaction depends on how much time spent with family and how much time spent on the work vis-à-vis. This varies from person to person. However, the quality time spent with the family or quality time spends in the work matters for the job satisfaction. It further directs to bring policies and schemes for supporting the employee to get satisfaction in the personal life. The employee's quality of work-life helps them maintain a work-life balance to be productive and committed at work. The organization has to devise the policies to help the workers to get life satisfaction and job satisfaction such as flexi-time work schedules, Flexi place or telecommuting, job-sharing, parttime, sabbaticals or career breaks. These policies may help to get satisfaction in life and further which leads get satisfaction on the job to retain the manpower in the organization.

\section{Perception on Institution}

The perception of the employee on the organization may positive or negative. When the employee perceives positively he feels trust and comfort. He may work effectively with commitment. When the employee perceives negatively, he perceives that his workplace as threatening or demanding workplace. The organization has to help the 
worker at the time of joining and facilitate comfort in the workplace so that employees will have trust in the organization. This helps the employee to work effectively and the employee may get retained in the organization.

\section{Emotional Intelligence of the Leaders}

The emotional intelligence of the leaders is one of the factors to improve the work-life balance. The employee may be in a different kind of emotional situation that the leader has to handle properly. The leaders have to handle the employee with emotional intelligence. The emotions can turnout positive and help the employee to contribute to their work. The leader's emotional intelligence has an impact on the quality of work-life and employee performance. The previous studies reveal that leaders' emotional intelligence is positively linked with the quality of work-life and it can be considered as a strong factor in the quality of work-life and employee performance. This study reveals that 86.7 percentages of people expressed that their immediate supervisor understands emotions and helping them in the workplace. It is around 13.3 percentage of persons expressed that they are not understanding the emotions of others. The emotional intelligence of the leaders also contributes to work-life balance. Leaders must understand emotion and help the workers to work with a comfortable work environment.

\section{Clear responsibility from Immediate Supervisor}

It is important to provide clear responsibilities from the immediate supervisor. Job clarity may help them to perceive work-life balance among the workers. If the employees do not get any clear responsibilities then they may get into confusion which would lead to lesser contribution in the workplace. Higher the Job clarity and higher the contribution by the workers. Higher the contribution helps to get job satisfaction as well as work-life balance. This study reveals that 80 percentages of the respondent get clear responsibilities from the immediate supervisors. It is around 20 percentages of the respondents expressed that they are not getting clear responsibilities.

\section{Person`s Wellbeing}

The person`s well being is one of the important factors for balancing the work-life balance. The employee well being is to be recognized to be vital for the organizational growth and effectiveness. Psychological well-being refers to positive psychological traits, such as self-acceptance, satisfaction, hope, or optimism.

The person's personality can be defined as the total of ways in which an individual reacts to and interact with others. The previous study on the personality traits study conducted and found that extraversion is related to greater facilitation between work and family roles do not relate to conflicts. It is also observed that proactive personalities may take steps to engage themselves and contribute to the organization. The person may face various situations to balance work life and family, the situations such as support from colleagues, number of children, job resources, and commitment may help to maintain a work-life balance. It is important to review that the situation of workers that those are facing difficulty to maintain work-life balance.

\section{Trusting and getting support from Co-workers}

Co-workers support is one of the important solutions to sharing the workload, which helps each other to attend the personal work and this would help to maintain the work-life balance. The co-worker's support in the workplace and job resources to positively help cope with the work-life balance while unfair criticism at a job has a negative relation with work-life balance among university teachers. The organization may inculcate the environment of work culture towards sharing the workload to maintain the work-life balance. This study reveals that 93.7 percent of respondents are trusted their co-workers and only 6.3 percentages of respondents did not trust the co-workers. If they do not trust their co-workers, they may get support from the Co-worker. This is the study also reveals that 90 percent of teachers can get support from their co-workers and 10 percentage of workers are not able to get support from the Co-workers. However, the administrative rules and formalities may be followed at the macro level. The facilitation of work-life balance at the micro-level helps to maintain work-life balance among faculties of the universities. 


\section{Use of Technology}

It is important to use technology to reduce the work and enhance the productivity of the workers. The use of technology would ease the labor and reduce the workload among the workers. When the employee uses the technologies, they may able to balance the work-life balance. This study reveals that 93.3 percentages of people can adopt the technology to enhance the work and 6.7 percentages of the respondents are not using technology to enhance the work. Technology also one of the factors which help to balance work-life balance by reducing the time of operation in the workplace.

\section{More number of children}

The workers may find it difficult to maintain a work-life balance when they have more number of children and may not face difficulty those who are having fewer children. Children with younger age may find it difficult to manage work-life balance than children with older age. However, these should be studied and helped to maintain a work-life balance. The previous studies reveal that Padma and Reddy( 2013) conducted a study among teachers from various schools located in Hyderabad and Andhra Pradesh, India to investigate the influence of child demographics namely; the number of children and their age on Work-Life Balance. The results revealed that school teachers with more number of children (three children) and also the childless teachers perceived similar Work-Life Balance. This study reveals that around 43.3 Percentage of persons do not have any children, 50 Percentage of respondents having 1-2 children, and 6.7 percentages of people having more than three children. Number of children also one of the factors to manage the work-life balance. Further study can be taken up for better understanding in this area. We may perceive that parents with more than three small children may find it difficult to manage the work-life balance. Parents with no children can able to manage the work-life balance.

\section{Gender: Work-Life Balance}

The women were working 40 hours per week and have more responsibility in the house. They tend to face difficulty in the family as well as work. It is a culture that only women work in the house, not men. There is always a multi taking job waiting for women who work in Institutions. They may find it difficult to manage the work-life balance. The organizations with ineffective work arrangements, long working hours, poor working conditions, pressurized work environment, and payment of poor wages may be responsible for monotony, frustration, and stress in the work among employees which leads to work-life imbalance. This study found that there is a relationship between gender and the ability to manage work-life balance by using Chi-Square Test (p-value: 0.025). The result indicates that women can manage the work-life balance than a man. Gender is an important factor that affects work-life balance. It throws light to take a study related to gender and work-life balance for a better understanding of these issues. The women can start alternative economic activities or Social entrepreneurship. These economic activities require assets to start up. The higher livelihood assets lead to higher stability in their economic activities ( Rubavel M, 2019). It will also help the women members to manage work-life balance.

\section{Benefits of Work-Life balance}

Managing the work and life would benefit the personal life as well as organizational ( Sudarsan N 2014). The personal benefit such as better physical and mental health, Greater sense of Job satisfaction, increased marital satisfaction, increased life satisfaction, leisure satisfaction, reduced job stress level, enhanced control over work-life environment, and better performance in the family. The organizational outcomes reflect in such as work satisfaction, career satisfaction, organizational commitment, better job performance, and lesser turnover of employees in various organizations.

\section{Recommendation for managing Work-Life Balance}

1. Work-life balance policies should be introduced such as Flexible working hours, adoption assistance, work at home, educational assistance, health assistance, housing assistance, and job sharing. These policies may help the employee to have trust and commitment towards the Organization.

2. The employers can promote a positive work-life culture by getting support from the Co-worker. 
3. Day-to-day support and space for expressing problems to the supervisors and co-workers to promote worklife balance within the organization.

4. Encouraging workers to work at home. People work more hours at home than in the office may enjoy the work because they may have more choices and control over their time.

5. The workers should be given opportunities to develop themselves and to take responsibility to participate in the process of decision-making in the organization.

6. The provision of flexibility in the workplace would help the employee to work with commitment to the organization.

7. The household work should be shared by the men also such as cooking, cleaning, and look after children and family members.

8. The women members should be provided with part-time jobs, tale-commuting, job sharing, paid leave, and quality affordable childcare and workplace flexibility (Laura, 1999).

9. The government should provide self-employment for women would be helpful, as self-employed women may find it easier to overcome the work-life conflict.

10. Sensitization to the employers on work-life balance is an important (Kumari k. Thriveni, Devi V. Rama, 2012).

11. Offer scheduling of flexi-time, where employees can provide their input on their preferred work schedule (Ritu Atheya \& Renu Arora,2014)

12. Encourage employees to take frequent breaks and drink water to solve the problem of dehydration and go to the restroom (at least once every two hours).

13. Increase the strength of the manpower by introducing lesser working hours. The employee may not like long working hours.

14. Employees should be allowed to select a choice of work in their allocated work.

\section{Conclusion}

This paper described the situation of teachers and faculty members and reviewed the factors that affect work-life balance such as work satisfaction, perception of the organization, emotional intelligence of the leaders, well being were discussed to explore better understanding on the Work-Life Balance to get meaningful inference. The persons with commitment bring various positive implications in the personal life as well as organizational life. It is important to think of implementing the policies on work-life balance. In a few cases, the committed employee may not able to balance the Work-life balance. However, Work-life balance studies needs careful attention between the conceptualization and operationalization. This review throws light to search on the various factors and how these factors influence the work-life balance. This study had recommended a few points to manage the work-life balance. However, the study gives a great thrust on the work-life balance of the workers, Teachers, and professionals. The policies need to be framed with careful operational guidelines to the implementation of work-life balance to improve the performance and productivity and also help the workers to enjoy and manage the work-life balance. Worker friendly policies, guidelines, and rules to be framed to support the work-life balance. Women should be supported to balance of work-life to create productive and committed workforce in the various institutions and to lead a joyful and satisfying life.

\section{References}

[1]. Arun Rotti et. al, (2016) Work-life balance: a concern for university employees, international journal of management, information technology and engineering, vol 4, issue 4, pp 1-8.

[2]. Toyaz Shekhar (2016), Work life balance \& Employee Engagement, International Journal of Education and Psychological Research, Vol 5, Issue 1, pp 32-341.

[3]. Shobitha Poulose et, al. Work Life Balance: A Conceptual Review. International Journal of Advances in Management and Economics. Pp 1-13.

[4]. Ioan Lazar ( 2010), The Role of Work-Life Balance Practices in Order to Improve Organizational Performance, European Research Studies, Vol 13, Issue 1, pp 201-204 
[5]. Diwinder Kaur Arora et al,(2015) Empirical analysis of work life balance policies and its impact on employee's job satisfaction and performance: Descriptive statistical approach, American Journal of Theoretical and Applied Statistics, Vol 4, (2) pp 33-43.

[6]. Diljot Soin (2011) stress, well-being and work/life balance among full-time and part-time working women, Global Journal of business management, vol 5, issue 2, pp 9-15.

[7]. Mohd Abdul Nayeem \& Manas Ranjan Tripathy( 2012) Work-Life Balance among Teachers of Technical Institutions, The Indian Journal of Industrial Relations, Vol. 47, No. 4, pp724-736.

[8]. Ritu Atheya \& Renu Arora,2014, Stress and Its Brunt on Employee's Work-Life Balance (Wlb): A Conceptual Study, IOSR Journal Of Humanities And Social Science (IOSR-JHSS) Volume 19, Issue 3, Ver. V (Mar. 2014), PP 57-62.

[9]. MacInnes, J. (2005). Work-life balance and the demand for reduction in working hours: Evidence from the British Social Attitudes Survey 2002. British Journal of Industrial Relations, 43(2), 273-295.

[10].Kossek, E. E., Lobel, S. A., \& Brown, J. (2006). Human resource strategies to manage workforce diversity. Handbook of workplace diversity, 53-74.

[11].McCrae, R. R., \& Costa Jr, P. T. (1999). A five-factor theory of personality. Handbook of personality: Theory and research, 2(1999), 139-153.

[12].Ward, M. E., \& Sloane, P. J. (2000). Non-pecuniary advantages versus pecuniary disadvantages; job satisfaction among male and female academics in Scottish universities. Scottish Journal of Political Economy, 47(3), 273-303.

[13].Mani, V. (2013). Work life balance and women professionals. Global Journal of Management And Business Research.

[14].Kumari, K. T., \& Rama Devi, V. (2013). Work-Life Balance Employee-A Challenge for the Employee and the Employer in 21 st Century.

[15].Sudha, J., \& Karthikeyan, P. (2014). Work life balance of women employee: A literature review. International Journal of Management Research and Reviews, 4(8), 797.

[16].Kabeer, N., Sudarshan, R., \& Milward, K. (Eds.). (2013). Organizing women workers in the informal economy: Beyond the weapons of the weak. Zed Books Ltd.

[17].Dr. J.Karunyal, J. Judith caroline and Dr.V.Vanitha (2015) Work-life Balance of Women Workers in the American college, Human Rights International Research Journal: Volume 3 Issue 1 (2015) pp 230-232.

[18]. Rubavel, M. (2019). Situational Analysis on Access of Livelihood Capitals in Livelihoods of Poor Households. IRAInternational Journal of Management \& Social Sciences (ISSN 2455-2267), 15(4), 115-121. 